\title{
Analysis of plateletpheresis donor deferral rate in family replacement donors and volunteer donors: A brief review of the China Chongqing area
}

\author{
Jun Li ${ }^{1}$, Lan $\mathrm{Wei}^{2}$, Tao Zhang ${ }^{3}$, Daiquan Xia ${ }^{4 *}$ \\ ${ }^{1}$ Department of Apheresis Component, Chongqing Blood Center, Chongqing, 400015, China; \\ ${ }^{2}$ Laboratory of Blood Screening, Chongqing Blood Center, Chongqing, 400015, China; \\ ${ }^{3}$ The Institute of Blood Transfusion, Chongqing, 400015, China; \\ ${ }^{4}$ Department of Business, Chongqing Blood Center, Chongqing, 400015, China
}

\begin{abstract}
In order to ensure an adequate and safe blood supply, the plateletpheresis donor deferral rate in family replacement donors and volunteer donors were analyzed in this study. The study was undertaken in the Chongqing Blood Center, China. Nucleic acid testing(NAT) and ELISA were applied to assess hepatitis B virus surface antigen (HBsAg), antibodies against hepatitis $\mathrm{C}$ virus (anti-HCV), human immunodeficiency virus (HIV) and Treponema palladium (TP) in plateletpheresis donors. From January 2015 to December 2016, a total of 17,342 plateletpheresis donors in the Chongqing Blood Center were enrolled in this study. Among the 3,642 plateletpheresis donors, $21.00 \%$ were younger than 25 , followed by 26-35 years group (41.19\%), 36-45 years group (22.46\%), 46-55 years group (13.97\%) and 56-60 years group (1.38\%). Replacement and voluntary donors contributed $5,305(30.59 \%)$ and $12,037(69.41 \%)$, respectively. Among all the plateletpheresis donors, $194(1.12 \%)$ were deferred because of seropositive serology. Replacement and voluntary deferred donors comprised $109(2.05 \%)$ and $85(0.68 \%)$, respectively $(P<0.05)$. Among the deferred donors, $194(1.12 \%)$ were seropositive for HBsAg $(0.44 \%)$, followed by anti-HCV $(0.28 \%)$, TP $(0.24 \%)$ and HIV $(0.15 \%)$. Prevalence deferred females contributed $67(1.60 \%)$, while males contributed $127(0.97 \%)$ of the deferred cases, respectively $(P<0.05)$. Deferral rate was highest among the $46-55$ years group (1.65\%) followed by the $36-45$ years group (1.63\%). The other groups were less than $1 \%$. It is necessary to reduce family replacement donors and replace them with regular volunteer donors, and to improve blood donor retention strategies to boost the regular blood donors' motivation. In addition to increasing and maintaining volunteer supply, it is desirable to keep the deferral rate at a low level, to ensure an adequate and safe blood supply.
\end{abstract}

Keywords: plateletpheresis, screening, deferral, donors

\section{INTRODUCTION}

Blood transfusion is a replacement therapy, which calls for products of human origin. Apheresis component collection is a rapidly growing area in the blood collection field ${ }^{[1]}$. Single donor plateletpheresis has numerous advantages over random donor platelets which include a decreased risk of transfusion-transmitted infections, bacterial contamination and abnormal immunization. Because of these advantages, the use of plateletpheresis is increasing year by year, which ne-

\footnotetext{
*Correspondence to: Daiquan Xia, Chongqing Blood Center, 1 Road Guihuayuan, Yuzhong district, Chongqing, 400015, China.E-mail: alex42014452@foxmail.com.

The authors state that there is no conflict of interest associated with this publication.
} 
cessitates the need for more plateletpheresis donors. In developing countries like China, a shortage exists. Major plateletpheresis donors are usually from voluntary donors, with a small number coming from family replacement donors. Despite the stringently advocated concerns regarding family replacement donors' blood safety, family replacement donors have certain differences. Due to these differences, decreasing family replacement donors would certainly increase viral safety. To ensure a safe blood supply, plateletpheresis donor screening is particularly important. There is therefore a need to reexamine the evidence and policy regarding the safety characteristics of family replacement donors. In this study, we conducted a retrospective analysis for plateletpheresis donor deferral rates between voluntary donors and family replacement donors in Chongqing Blood Center from January 2015 to December 2016. The prevalence of transfusion-transmissible infections hepatitis B virus (HBV), hepatitis C virus (HCV), human immunodeficiency (HIV) and Treponema palladium (TP) among family replacement donors and voluntary donors were analyzed. Our study clearly reveals the overall deferral rate in plateletpheresis donors from the Chongqing Blood Center and also provides a scientifically acceptable practice for targeted recruitment and retention to increase donations.

\section{MATERIALS AND METHODS}

\section{Donors and criteria for plateletpheresis donations}

The study was undertaken in a period from January 2015 to December 2016. All potential donors underwent strict screening to determine their eligibility to donate (GB 18467-2011). The process included identification, a questionnaire-based interview, a brief physical examination, and serological tests to detect major transfusion-transmissible pathogens. Basic criteria for plateletpheresis predonors were related to body weight and gender, males and females should not weigh less than $50 \mathrm{~kg}$ and $45 \mathrm{~kg}$, respectively; hemoglobin concentration should be at least $120 \mathrm{~g} / \mathrm{L}$ for males and $115 \mathrm{~g} / \mathrm{L}$ for females; the age range was from 18 to 60 years; ALT should be no more than $50 \mathrm{U} / \mathrm{L}$; systolic BP between $90-140 \mathrm{mmHg}$ and diastolic BP between 60-90 $\mathrm{mmHg}$ were accepted for blood donation. For the plateletpheresis donations, further screening criteria included: platelet count $\geqslant 150 \times 10^{9} / \mathrm{L}$ and $<450 \times 10^{9} / \mathrm{L}$; a gap of 3 months from the last whole blood donation or 14 days from their last plateletpheresis donation; no intake of non-steroidal anti-inflammatory drugs in the last seven days; adequate venous access. Informed consent was ob- tained from all individual participants included in the study.

\section{ELISA and nucleic acid testing (NAT) screening}

All serological studies were performed using ELISA and NAT system. The ELISA and NAT were performed according to the manufacturers' instructions.

\section{Statistical analysis}

Data were analyzed using IBM SPSS Statistics, version 18.0 (Chicago, USA). The graphic presentation was achieved using Graph Pad Prism 6.0 and Excel 2010 software. Qualitative data are described as numbers and percentages and were compared using the chisquare test $\left(\chi^{2}\right) . P<0.05$ was taken to mean a significant difference.

\section{RESULTS}

A total of 17,342 plateletpheresis donors in the Chongqing Blood Center were enrolled in this study during the period January 2015 to December 2016. Of those, 13,151 were males $(75.83 \%)$ and 4,191 were females $(24.17 \%)$, the male-female ratio being observed as 3.14:1.00. Among all the plateletpheresis donors, 3,642 were under the age of 25 (21.00\%), followed by the 26-35 years group (41.19\%), 36-45 years group (22.46\%), 46-55 years group (13.97\%) and 56-60 years group (1.38\%) (Table 1). Replacement and voluntary donors contributed 5,305 (30.59\%) and 12,037 (69.41\%), respectively(Table 2). Among all the plateletpheresis donors, 194 (1.12\%) were deferred because of seropositive serology. Replacement and voluntary deferred donors comprised $109(2.05 \%)$ and $85(0.68 \%)$, respectively $(P<0.05)$. Among the deferred donors, $194(1.12 \%)$ were seropositive for HBsAg $(0.44 \%)$, anti-HCV $(0.28 \%)$, TP $(0.24 \%)$ and HIV $(0.15 \%)$ (Table 3). Prevalence deferred females contributed 67 (1.60\%), while males contributed 127 $(0.97 \%)$ of the deferred cases, respectively $(P<0.05$, Table 4). Deferral rate was highest among the 46-55 years group ( $1.65 \%$ ) followed by the $36-45$ years group (1.63\%). In the other groups deferral was less than $1 \%$ (Table 5).

Table 1 Comparison of age features of voluntary donors and family replacement donors $(n)$

\begin{tabular}{|c|c|c|c|c|c|}
\hline & \multicolumn{3}{|c|}{$18-25$ у $26-35$ у $36-45$ y } & $46-55$ & $56-60 y$ \\
\hline Voluntary donors & 2,530 & 4,889 & 2,634 & 1,774 & 210 \\
\hline $\begin{array}{l}\text { Family replacement } \\
\text { donors }\end{array}$ & 1,112 & 2,254 & 1,261 & 649 & 29 \\
\hline Total & 3,642 & 7,143 & 3,895 & 2,423 & \\
\hline
\end{tabular}

$\chi^{2}=245.272, P<0.001$. 
Table 2 Comparison of gender features of voluntary donors and family replacement donors $(n)$

\begin{tabular}{lcc}
\hline Groups & Females & Males \\
\hline Voluntary donors & 2,554 & 9,483 \\
Family replacement donors & 1,637 & 3,668 \\
Total & 12,037 & 5,305 \\
\hline
\end{tabular}

$\chi^{2}=186.707, P<0.001$.

Table 3 Permanent deferral by age between voluntary donors and family replacement donors $(n)$

\begin{tabular}{lcccc}
\hline Groups & HBsAg & TP & anti-HCV & HIV \\
\hline Voluntary donors & 35 & 17 & 21 & 12 \\
Family replacement donors & 42 & 25 & 28 & 14 \\
Total & 77 & 42 & 49 & 26 \\
\hline
\end{tabular}

$\chi^{2}=0.350, P=0.950$.

Table 4 Prevalence of transfusion-transmissible in-

\begin{tabular}{lcccc} 
& \multicolumn{2}{c}{ fections according to gender } & $(n)$ \\
\hline Gender & HBsAg & TP & anti-HCV & HIV \\
\hline Females & 28 & 18 & 13 & 8 \\
Males & 49 & 24 & 36 & 18 \\
Total & 77 & 42 & 49 & 26 \\
\hline
\end{tabular}

$\chi^{2}=2.952, P=0.399$.

Table 5 Prevalence of transfusion-transmissible in-

\begin{tabular}{lcrcr} 
& \multicolumn{3}{c}{ fections according to age groups } & $(n)$ \\
\hline Age & HBsAg & TP & anti-HCV & HIV \\
\hline $18-25$ y & 11 & 6 & 11 & 4 \\
$26-35$ y & 28 & 9 & 13 & 8 \\
$36-45$ y & 19 & 15 & 17 & 12 \\
$46-55$ y & 18 & 12 & 8 & 2 \\
$56-60$ y & 1 & 0 & 0 & 0 \\
Total & 77 & 42 & 49 & 26 \\
\hline
\end{tabular}

$\chi^{2}=11.991, P=0.214$.

\section{DISCUSSION}

Blood transfusion is an important medical procedure that in a number of situations can help save lives, however, there are still some risks involved. WHO has developed some strategies to minimize these risks, one of them is the promotion of blood collections from voluntary donors. Sometimes, we are confronted with problems of blood shortages, because of the insufficient number of volunteer blood donors. To avoid deaths resulting from the lack of blood products, most institutions call on family replacement donors.

The aim of this study was to analyze the difference in plateletpheresis donor deferral rate between voluntary donors and family replacement donors from Chongqing area of China. Among the plateletpheresis donors in our report, $1.12 \%$ (194) were deferred due to transfusiontransmitted infections. However, Pujani et al. observed a much higher deferral rate of $8.04 \%{ }^{[2]}$. Our results revealed that the overall prevalence of transfusiontransmissible infections were significantly higher in family replacement donors $(2.05 \%, 109 / 5,305)$ than in voluntary donors $(0.68 \%, 85 / 12,037)(P<0.05)$. Our study clearly reveals that the overall prevalence of HBsAg, anti-HCV, HIV and TP in voluntary donors is much lower than those in family replacement donors. In order to minimize the risks, in most cases, hospitals and blood service centers make substantial efforts to eliminate family replacement donors as the main source. But in cases of blood shortages, as an emergency measure, family replacement donors are a supplement of voluntary blood donation and play a positive role. Contrary to traditional recruitment methods, family replacement donoration have many potential risks. It's partly because that blood donors donating platelets, being relatives or friends often ignore the health consultation process. It is possible that they know they are partaking in a high risk behavior in some cases and therefore should not donate blood, because of their physical condition or other circumstances. Moreover, most donors are unable to assess their health status and determine whether they are suitable for blood donation before donating blood. Although all of them are screened, their donation still exist obviously higher risk than voluntary donors.

It is necessary to reduce family replacement donors and replace them with regular volunteer donors. In some ways, devising a strategy to convert family replacement donors into repeat donators would be efficient. In addition, it is desirable to improve blood donor retention strategies to boost the regular blood donors' motivation ${ }^{[3,4]}$. Increasing the number of voluntary donors is the best way to achieve the safest blood, as they are usually younger and have better education, which creates awareness among them about the importance of donation and the risks of transmitting different viral infections. Hence it is imperative that potential plateletpheresis donors be equipped with knowledge pertaining to deferral criteria as this might help eliminate the rejection factor when one is deferred and increases the probability of returning at a later date. Meanwhile, screening should effectively decrease the deferral rate and donation adverse reactions ${ }^{[5-7]}$. Hence, a wide range of strategies are required for effective donor recruitment and retention. Traditional methods such as telephone calls, messages, and public service announcements, while still valuable, may be less appealing and less effective for certain donors ${ }^{[8,9]}$. The plateletpheresis donor mobile application (APP) is a promising approach for recruitment and continued donor engagement ${ }^{[10]}$. APP on portable devices have the potential to mobilize donors in response to demand quickly, provide customized support and efficient scheduling for individual donors. Not surprisingly, some blood centers including the Chongqing Blood Center have already launched or been planning to launch a plateletpheresis donor mobile APP. Making donation appointments in the current 
APP, according to the plateletpheresis donors' age, sex, education level, etc.

As a first attempt to characterize features of deferral rate between voluntary donors and family replacement donors in Chongqing area of China, some caveats need to be considered in the interpretation of these findings. Firstly, data collected were restricted to blood centers in one region and we should be cautious about its generalizability. Accordingly, it would be enlightening to conduct multi-regional and multi-center studies to confirm the current findings. Secondly, for several reasons we were only able to collect statistics for a comparatively short time and this limits a more detailed analysis. Thus, further studies are needed to provide more detailed information. Nevertheless, irrespective of these considerations, we believe that our findings are worthy of comparison with future investigations.

\section{Acknowledgements and funding}

This research was financially supported by the Medical Research Foundation of Chongqing (No. 2016MSXM110.). We thank all colleagues for their collaboration and assistance. We thank all of the donors and staff at the blood donation facility.

\section{References}

[1] Burgstaler EA. Blood component collection by apheresis. J Clin Apher, 2006, 21(2): 142-51.

[2] Pujani M, Jyotsna PL, Bahadur S, et al. Donor deferral characteristics for plateletpheresis at a tertiary care center in India- a retrospective analysis. J Clin Diagn Res, 2014, 8(7): FC01-3.

[3] France JL, France CR, Carlson BW, et al. Motivating first-time, group $\mathrm{O}$ blood donors to return: Rationale and design of a randomized controlled trial of a postdonation telephone interview. Contemp Clin Trials, 2015,44: 64-9.

[4] Guiddi P, Alfieri S, Marta E, et al. New donors, loyal donors, and regular donors: Which motivations sustain blood donation? Transfus Apher Sci, 2015, 52(3): 339-44.

[5] Inaba S, Takanashi M, Matsuzaki K, et al. Analysis of a questionnaire on adverse reactions to blood donation in Japan. Transfus Apher Sci, 2013, 48(1): 21-34.

[6] Patidar GK, Sharma RR, Marwaha N. Frequency of adverse events in plateletpheresis donors in regional transfusion centre in North India. Transfus Apher Sci, 2013, 49(2): 244-8.

[7] Tomita T, Takayanagi M, Kiwada K, et al. Vasovagal reactions in apheresis donors. Transfusion, 2002, 42(12): 1561-6.

[8] Bruhin A, Goette L, Roethlisberger A, et al. Call of duty: the effects of phone calls on blood donor motivation. Transfusion, 2015, 55(11): 2645-52.

[9] Junod Perron N, Dao MD, Righini NC, et al. Textmessaging versus telephone reminders to reduce missed appointments in an academic primary care clinic: a randomized controlled trial. BMC Health Serv Res, 2013, 13: 125.

[10] Yuan S, Chang S, Uyeno K, et al. Blood donation mobile applications: are donors ready? Transfusion, 2016, 56(3): 614-21.

(Received 19 July 2017, Revised 06 August 2017, Accepted 09 August 2017) 